\title{
USE OF ION EXCHANGE MEMBRANES IN ROUTINE SOIL TESTING
}

\author{
P. Qian and J. J. Schoenau \\ University of Saskatchewan
}

\begin{abstract}
We developed and assessed a method for simultaneous extraction of plant available nitrogen, phosphorus, sulfur and potassium using anion and cation exchange membranes (ACEM). The technique was found to be highly suitable for routine soil testing due to its simplicity, rapidness and accuracy. The study compared the amount of nutrients extracted by ACEM with conventional chemical-based extractants for $\mathrm{P}$ and $\mathrm{K}(0.5 \mathrm{M} \mathrm{NaHCO} 3)$ and $\mathrm{N}$ and $\mathrm{S}\left(0.001 \mathrm{M} \mathrm{CaCl}_{2}\right)$ for 135 soil samples representing a wide range of soil types in Western Canada. The nutrient availability predicted by ACEM was significantly correlated with the conventional methods. The correlation was not affected by the two different shaking times tested (one hour and 15 minutes), suggesting that extraction times as short as 15 minutes could be used in ACEM extraction. To evaluate the relative ability of ACEM and the conventional tests to predict actual nutrient availability to plants, canola plants were grown on soils in the growth chamber and actual plant uptake was compared to test-predicted nutrient availability. Phosphorus and potassium uptake by canola plants was more closely correlated with ACEM extractable $\mathrm{P}$ and $\mathrm{K}\left(\mathrm{r}^{2}=0.84 * * *\right.$ and $\left.0.54 * * *\right)$ than with $0.5 \mathrm{M}$ $\mathrm{NaHCO}_{3} \mathrm{P}$ and $\mathrm{K}\left(\mathrm{r}^{2}=0.70^{* * *}\right.$ and $\left.0.37 * * *\right)$. Also, nitrogen and sulfur uptake by canola plants was significantly correlated with ACEM extractable- $\mathrm{NO}_{3}$ and $-\mathrm{SO}_{4}\left(\mathrm{r}^{2}=0.60 * * *\right.$ and $\left.0.70^{* * *}\right)$ and with $\mathrm{CaCl}_{2}$ extractable- $\mathrm{NO}_{3}$ and $-\mathrm{SO}_{4}\left(\mathrm{r}^{2}=0.57 * * *\right.$ and $\left.0.61 * * *\right)$. Availability of all four macronutrients can be assessed in a single ACEM extraction. The higher correlation with plant uptake suggests that ACEM is a better index of macronutrient availability than conventional methods. The ACEM soil test could be readily adopted in routine soil analysis because of low cost and simplicity as well as its consistency over a wide range of soil types.
\end{abstract}

\section{INTRODUCTION}

Ion exchange resin extractions have been used to assess the availability of plant nutrients in research applications for almost four decades (Pratt, 1951 and Amer et al., 1955). The majority of this work involved using anion exchange resin beads to provide an estimate of biologically available P (Amer et al., 1955; Moser et al., 1959; Cooke and Hislop, 1963; Walmsley and Cornforth (1973); Bowman et al., 1978; Sibbesen, 1978, 1983; Nesse et al., 1988; Yang and Jacobsen, 1990). The use of cation exchange resin was first reported by Pratt (1951) for extraction of available K in soils. Later, cation exchange resin was used to study the comparative rates of release of $\mathrm{K}$ by different micas (Frigenbaum et al., 1981) .Martin and Sparks (1983) used exchange resins to examine the kinetics of nonexchangeable K release from soils. Heming and Rowell (1985) also studied the release of K from soil aggregates using cation exchange resin. The exchange resin technique for measuring the $\mathrm{P}$ and $\mathrm{K}$ supplying power of the soil is based on movement of phosphate and potassium ions from soil particles to the soil solution, where they are adsorbed by the resin. The resin continually removes any ions which come into solution, thus preventing equilibrium of the ions between the solid phase and the solution. This mode of action is similar to the manner in which plant roots act to remove ions from the soil. Therefore, resins are thought to be a universal index of relative nutrient availability as compared to chemicalbased extractions which may be limited in scope due to thieir ability to remove only specific nutrient fractions. 
Originally, loose resin beads were used for extraction to estimate the bioavailability of phosphorus. A major problem in using loose beads was the difficulty in their separation from the soil following the extraction. This problem has been overcome by sewing up the beads in a bag (Sibbesen, 1977; Skogley et al., 1990; Yang et al., 1991). Several recent studies have reported that anion and cation exchange resin beads can be mixed, enclosed in mesh bags and used for simultaneous extraction of plant available nutrient ions (van Raij et al., 1986; Yang et al., 1990 ab; Skogley et al., 1990; Yang et al., 1991). Skogley et al. (1990) report on such a method termed the phytoavailability soil test (PST) which, through extraction for 2-3 days in saturated paste soil samples, will provide simultaneous assessment of $\mathrm{P}, \mathrm{K}$ and $\mathrm{S}$ availability. These workers observed a considerable improvement in the relationship between spring wheat $\mathrm{K}$ and $\mathrm{S}$ contents and test-predicted availability in the exchange resin extraction compared to conventional soil tests.

The extraction of soil nutrients using ion exchange resins in membrane form was first introduced by Saunders (1964). Saunders (1964) used an anion exchange membrane to extract soil phosphate and showed that its ability to estimate soil P was as good as resins in the bead form. Resin membrane techniques have recently been developed for the extraction of soil P (Saggar et al., 1990; Schoenau and Huang, 1991a). Schoenau and Huang (1991a) have reported that in testing for $\mathrm{P}$, the anion exchange membrane extraction procedure developed was superior to bicarbonate and water extractions due to low cost, simplicity, independence of soil type, and high correlation with plant uptake. Saggar et al. (1990) compared the amounts of $P$ extracted by shaking soils with resin membranes for 16-17 hours to $P$ removed by resin beads in bags for a number of New Zealand soils and found that amounts of $\mathrm{P}$ removed by membranes was closely correlated with that extracted by the resin bags. They observed that the bag procedure suffers from the disadvantage that the resin bags often trap fine root and soil particles which can only be removed by washing under pressure as well as problems with wear and tear on sealed edges of the bags.

In spite of the apparent advantages of resin method to assess the nutrient availability in soils, there is still lack of reports on the practical use of the resin beads or membranes in routine soil testing laboratories which process large number of soil samples. Schoenau and Huang (1991b) used mixed anion and cation exchange membranes (ACEM) to simultaneously extract plant available nitrate, phosphate, potassium and sulfate and reported high correlations between ACEM predicted availability and plant uptake of N,P, K and S, indicating that the ACEM approach could provide a multi-element soil test superior to any existing methodologies in routine soil testing. Since the number of soils evaluated was limited (Schoenau and Huang, 1991b), we felt it was necessary to expand the study to include a larger number of soil types in the evaluation. In order to make the resin membrane method more applicable to routine soil testing, this study included (1) the refinement of the ACEM method for routine soil testing in terms of making it as rapid and simple as possible, and (2) the evaluation of the ACEM method by comparison to conventional soil tests on a wide range of soils and by the correlation of soil test results with plant response through growth chamber experiments.

\section{MATERIALS AND METHODS}

\section{Soil test procedures}

One hundred and thirty five surface soil samples were selected from those submitted to the University of Saskatchewan Soil Testing Laboratory by farmers for routine analysis in 1991. The soil samples offered considerable diversity in terms of $\mathrm{pH}$, texture, electrical 
conductivity and available nutrient level (Table 1) and were chosen to represent all six soil zones in Saskatchewan. Anion and cation exchange membrane sheets (BDH) were cut into strips of $46 \times 10 \mathrm{~mm}$ for AEM and $40 \times 14 \mathrm{~mm}$ for CEM. Exchange membrane strips were washed in $0.5 \mathrm{M} \mathrm{NaHCO} 3$ and then stored in deionized water prior to use. The exchange membrane extraction method we used was similar to that outlined by Schoenau and Huang (1991 ab). The major modification was to use $125 \mathrm{ml}$ erlenmeyer flasks instead of $50 \mathrm{ml}$ polyethylene centrifuge tubes as erlenmeyer flasks are more commonly used in soil test laboratories. The ACEM extraction was performed as follows: A $3 \mathrm{~cm}^{3}$ scoop of soil was transferred to a $125 \mathrm{~mL}$ erlenmeyer flask and one strip of AEM and one strip of CEM was dropped in the flask. Following this, $35 \mathrm{~mL}$ of deionized water was added to the flask and the flask placed on a reciprocating shaker. One hour and 15 minute shaking times were compared. Following the shaking, the membrane strips were removed from the flask and rinsed with deionized water. The strips were then transferred to a clean flask containing 20 $\mathrm{mL}$ of $0.5 \mathrm{M} \mathrm{HCl}$ to elute (remove) the ions from the strip. One hour and 15 minute elution times were compared. After elution, the strips were removed from the eluent, washed in $\mathrm{NaHCO}_{3}$ for regeneration, and the nitrate and phosphorus concentrations in the $\mathrm{HCl}$ determined using routine automated colorimetry (LaChat flow injection autoanalyzer for nitrate and Technicon autoanalyzer for phosphorus). The concentrations of $\mathrm{K}$ and $\mathrm{S}$ in the eluent were determined using automated flame photometry and inductively coupled plasma emission spectrometry, respectively.

Table 1. Some properties of the soils used in the comparison study $(n=135)$

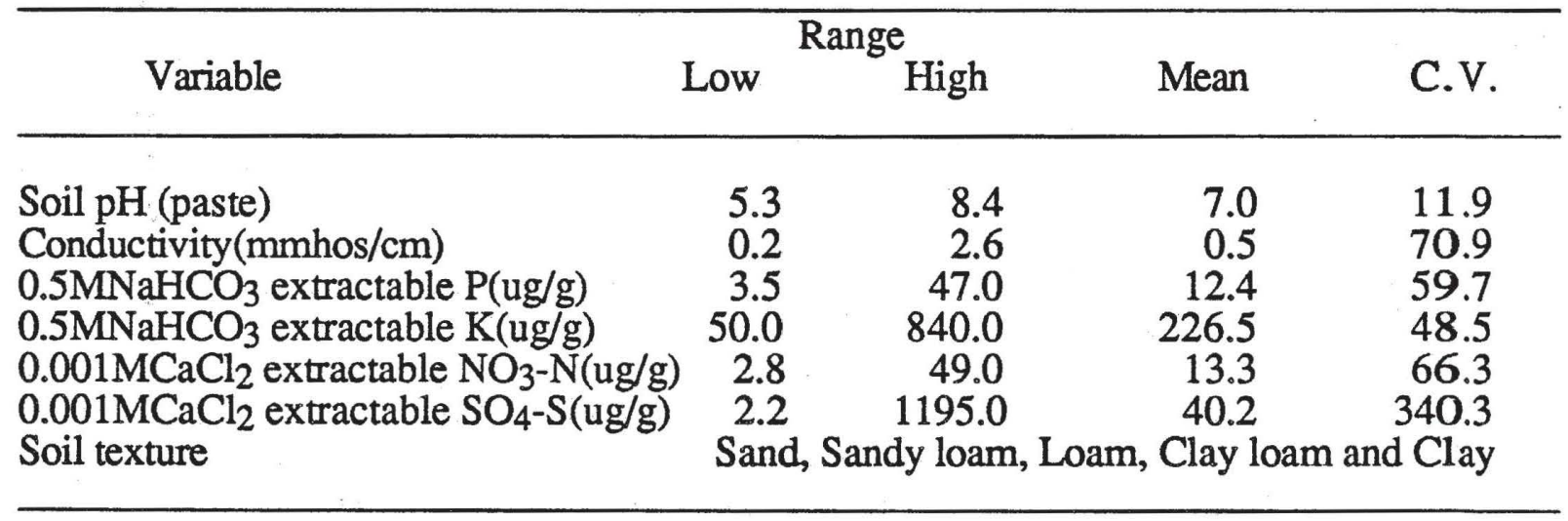

In the determination of bicarbonate (Olsen et al., 1954) extractable $\mathrm{P}$ and $\mathrm{K}$, a $3 \mathrm{~cm}^{3}$ scoop of soil was shaken with $60 \mathrm{~mL}$ of $0.5 \mathrm{M} \mathrm{NaHCO}_{3}$ for 30 minutes on a reciprocating shaker, decolored using activated carbon, and filtered. Phosphate in the extract was colorimetrically determined on the Technicon autoanalyzer using the acid molybdate blue procedure and $\mathrm{K}$ was determined using flame photometry. Soluble nitrate and sulfate were determined by shaking $25 \mathrm{~cm}^{3}$ of soil with $50 \mathrm{~mL}$ of $0.001 \mathrm{M} \mathrm{CaCl}$ for 30 minutes. Samples were then filtered and the nitrate and sulfate concentrations determined colorimetrically using the automated flow injection analysis system. The $\mathrm{NaHCO}_{3}$ and $\mathrm{CaCl}_{2}$ extraction is used on a routine basis by the Saskatchewan Soil Testing Laboratory in assessing macronutrient availability in farm samples. For P, we also compared ACEM to an extractant known as the Modified Kelowna extractant (Qian et al., 1991). The Modified Kelowna extractant (KM) is comprised of $0.25 \mathrm{~N} \mathrm{HOAc}$ and $0.015 \mathrm{~N} \mathrm{NH}_{4} \mathrm{~F}$ as well as 0.25 $\mathrm{M} \mathrm{NH}_{4} \mathrm{OAc}$ with a measured $\mathrm{pH}$ value of 4.9 . 


\section{Growth Chamber Study}

For the growth chamber study, thirty nine soil samples were selected so as to provide maximum contrast in nutrient availability and soil characteristics. The texture of soil used included sand, loam, clay and their transitive types. The $\mathrm{pH}$ and $\mathrm{EC}$ in 1:1 soil :water suspension was between 5.3 and 8.2 and from 0.2 to $2.6 \mathrm{mS} \mathrm{cm}^{-1}$, respectively. The sodium bicarbonate extractable $P$ and $K$ of the soils used ranged from 4 to $37 \mathrm{ug} \mathrm{g}^{-1}$ and from 55 to $385 \mathrm{ug} \mathrm{g}^{-1}$, respectively. The soil nitrate and sulfate in $0.001 \mathrm{M} \mathrm{CaCl}_{2}(1: 2)$ was between 4.8 and $49 \mathrm{ug} \mathrm{g}^{-1}$ and between 2.6 and $630 \mathrm{ug} \mathrm{g}^{-1}$. One hundred grams of each soil was measured into styrofoam pots. The experiment included minus $\mathrm{P}$, minus $\mathrm{K}$, minus $\mathrm{N}$ and minus $S$ treatments. A nutrient solution was applied to each pot (Table 2) before sowing the canola seeds (var. Westar).

Table 2. Nutrient added in each treatment

\begin{tabular}{ccccc}
\hline Treatment & \multicolumn{4}{c}{ Nutrient added $(\mathrm{mg} / 100 \mathrm{~g})$} \\
\cline { 2 - 5 } & $\mathrm{N}$ & $\mathrm{P}$ & $\mathrm{K}$ & $\mathrm{S}$ \\
\hline$-\mathrm{P}$ & 10 & -- & 20 & 5 \\
$-\mathrm{K}$ & 10 & 3 & - & 5 \\
$-\mathrm{N}$ & -- & 3 & 20 & 5 \\
$-\mathrm{S}$ & 10 & 3 & 20 & - \\
\hline
\end{tabular}

All soils were given a blanket micronutient treatment of $\mathrm{Cu}, \mathrm{Zn}, \mathrm{Mn}, \mathrm{Mo}$ and $\mathrm{B}$ at rate of $0.06,0.4,0.5,0.06$ and $0.15 \mathrm{mg} / 100 \mathrm{~g}$.

Approximately 8 to 10 seeds of canola were seeded into each pot and were thinned to 2 plants after emergence. All pots were watered twice a day to keep soil moisture at $90 \%$ of field capacity. The growth chamber temperature was set at $26^{\circ} \mathrm{C}$ daytime and $12^{\circ} \mathrm{C}$ at night. The pots were completely randomized and rotated every week. After 4 weeks, $100 \mathrm{ug} \mathrm{N} / \mathrm{g}$ and $50 \mathrm{ug} \mathrm{S} / \mathrm{g}$ were applied in solution to each of pots in the $-\mathrm{P}$ and $-\mathrm{K}$ treatments and $33 \mathrm{ug}$ $\mathrm{N} / \mathrm{g}$ to the $-\mathrm{S}$ treatment to ensure that deficiency did not limit growth .

Plants were harvested at 7 weeks (flowering), dried at $60^{\circ} \mathrm{C}$ and weighed for dry matter yield determination. Ground plant samples were digested in sulfuric acid-peroxide using a temperature-controlled digestion block (Thomas et al., 1967), followed by colorimetric determination of $\mathrm{P}$ and $\mathrm{N}$ and flame emission spectrometric determination of $\mathrm{K}$. For the determination of $\mathrm{S}$, ground samples were digested with sodium hypobromite (Tabatabai, 1982) and the $S$ content in the digested solution measured using inductively coupled plasma emission spectrometry.

\section{RESULTS AND DISCUSSION}

\section{Effect of extraction and elution times on nutrient extracted by ACEM}

Total time of analysis is a major factor when evaluating the suitability of a new methodology for routine soil testing. Until now, the extraction times reported for ion exchange resin methods have been 16 hours or longer (Sibbesen, 1977, van Raij et al., 1986, Nesse et al., 1988 and Saggar et al., 1990). Schoenau and Huang (1991a ) compared 1 hour, 6 hour, and 16 hour extraction times and found that, although the amounts of $P$ extracted were lower with shorter extraction time, there was no change in the ability of the test to predict $P$ availability to plants. Clearly, if extraction and elution times less than 1 hour 
could be used without loss of predictive ability, the method would be much more suitable for routine soil testing work. We initially compared 15 minute and 1 hour elution times and found that all nutrient ions could be effectively displaced from membranes by the $\mathrm{HCl}$ in 15 minutes. We compared extraction times of 1 hour to extraction times of 15 minutes for ACEM extractable phosphate, potassium, nitrate and sulfate for 135 soils (Table 3).

Table 3. Regression equations for relationships between nutrient extracted by ion exchange membrane in 15 minute versus 1 hour extraction time.

Phosphorus

$\operatorname{ACEM}_{15 \min }=-0.08+0.37$ ACEM $_{1 \text { hour }} \quad r^{2}=0.96 * * *$

Potassium

$\mathrm{ACEM}_{15 \mathrm{~min}}=26+0.48 \mathrm{ACEM}_{1 \text { hour }} \quad \mathrm{r}^{2}=0.57 * * *$

Nitrate

$\mathrm{ACEM}_{15} \min =-0.2+0.86 \mathrm{ACEM}_{1}$ hour

$\mathrm{r}^{2}=0.99 * * *$

Sulfate

$\mathrm{ACEM}_{15 \mathrm{~min}}=0.3+0.60 \mathrm{ACEM}_{1}$ hour $\quad \mathrm{r}^{2}=0.97 * * *$

For $\mathrm{P}$, we observed that the 15 minute extraction time resulted in extractable $\mathrm{P}$ levels that were about $40 \%$ of the values for 1 hour. However, there was no difference in predicted relative $\mathrm{P}$ availability in the soils as shown by the high correlation between the 15 minute and 1 hour ACEM $P\left(r^{2}=0.96^{* * *}\right)$. This highly significant correlation was not affected by soil $\mathrm{pH}$, soil texture and soil zone.

In the case of $\mathrm{K}$, the 15 minute ACEM extraction removed about $50 \%$ of that removed in a 1 hour extraction. However, the amounts extracted over the two extraction times were not as closely correlated for $\mathrm{K}\left(\mathrm{r}^{2}=0.57 * * *\right)$ compared to the other nutrients. This suggests that different soil $\mathrm{K}$ pools are measured over short versus longer extraction periods. Over shorter extractions, the K extracted by ACEM would mainly be comprised of soil solution $\mathrm{K}$ whereas over longer extraction periods a greater measure of the reserve or exchangeable $\mathrm{K}$ would be included. Stratification of all the soils tested into groups according to texture showed the lowest correlations between 15 minute and 1 hour extractions in clay soils $\left(\mathrm{r}^{2}=0.45^{*}\right)$. This is expected since in clay soils the absorbed $\mathrm{K}$ pool is most significant in relation to solution $\mathrm{K}$.

For ACEM extractable nitrate, the 15 minute ACEM removed about $86 \%$ of the nitrate removed in the 1 hour extraction. The 15 minute and 1 hour extractions were very closely correlated with minimal scatter $\left(\mathrm{r}^{2}=0.99 * * *\right)$. The close relationship between 15 minute and 1 hour extraction for nitrate is attributed to the lack of an adsorbed nutrient pool whose contribution could be affected by extraction time. Stratification of all the samples tested into groups according to $\mathrm{pH}$ and texture as well as soil zones showed highly significant correlations between 15 minute and 1 hour extractions in all groups $(\mathrm{p}=0.0001)$. A similar effect was observed for sulfate, with a close relationship between predicted availability for 15 minute and 1 hour extraction $\left(\mathrm{r}^{2}=0.97 * * *\right)$. 


\section{Relationship between nutrient extracted by ACEM and conventional soil tests.}

For all the soils tested, we observed a good correlation $\left(\mathrm{r}^{2}=0.74 * * *\right)$ between ACEM-P and $0.5 \mathrm{M} \mathrm{NaHCO}_{3}$ (Olsen) $\mathrm{P}$ (Fig. 1). Amounts of $\mathrm{P}$ extracted by ACEM were about 17 percent of the amounts removed in the Olsen test. An even stronger relationship $\left(\mathrm{r}^{2}=0.86^{* * *}\right)$ was observed between ACEM-P and KM-P, with the ACEM extracting about 15 percent of the $\mathrm{P}$ removed in the Modified Kelowna test. Exchange resin extractions are independent of soil type, providing a relative index of nutrient availability in all types of soil. The better agreement between ACEM and Modified Kelowna may be partly attributed to the inclusion of 34 soil samples with $\mathrm{pH}$ in the slightly acidic range (from 5.3 to 6.3). The sodium bicarbonate extraction is considered a suitable extractant only for neutral and alkaline soils (Olsen et al., 1954 and Shi, 1980), while the Modified Kelowna extractant has shown its suitability in all soil types (Qian et al., 1991).
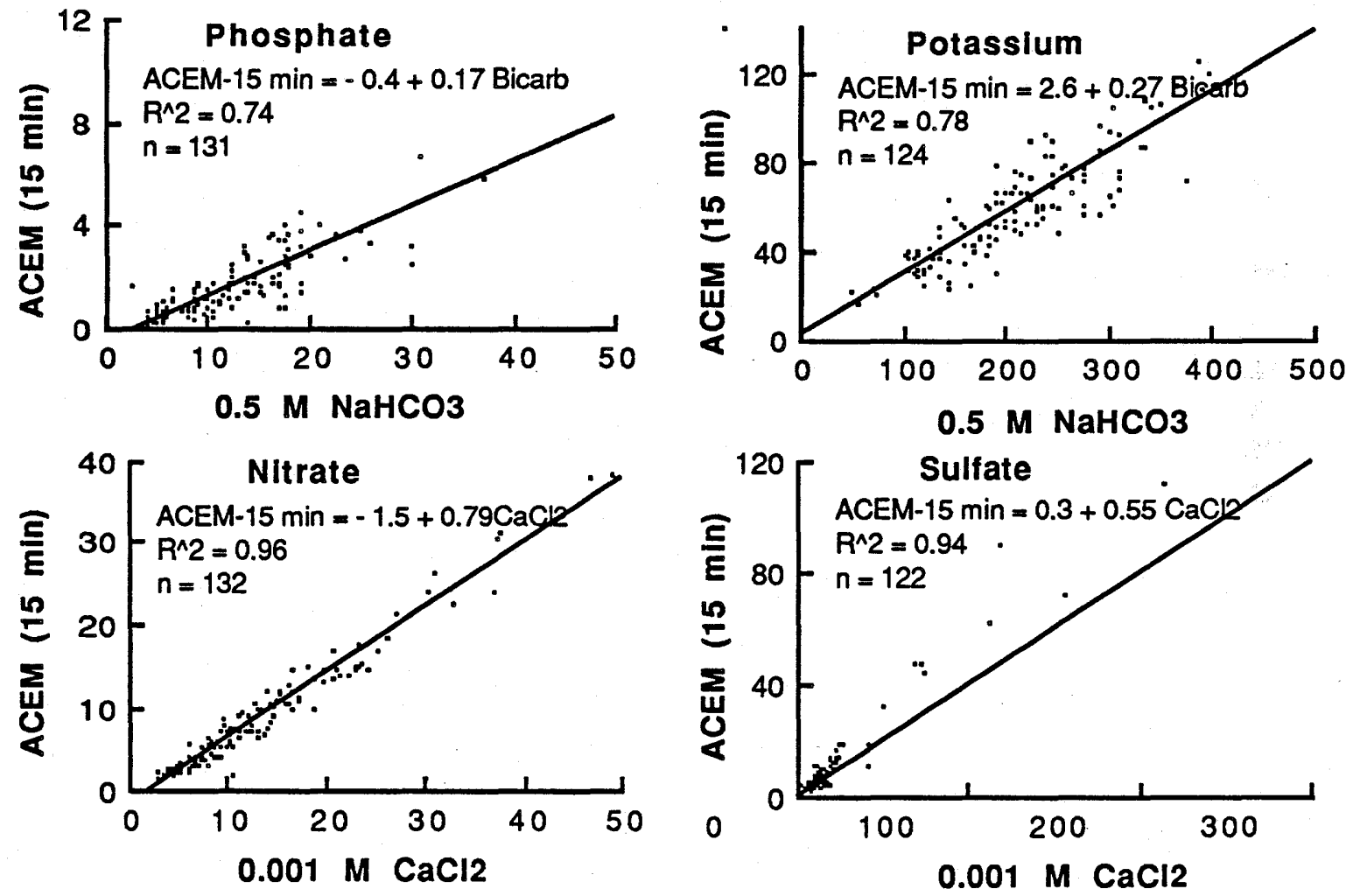

Fig. 1. Relationships between nutrient amounts (ug/g) extracted by ACEM and by conventional methods

We observed a reasonably close relationship $\left(\mathrm{r}^{2}=0.78^{* * *}\right)$ between the 15 minute $\mathrm{ACEM}$ and bicarbonate extractable $\mathrm{K}$ for the soils tested (Fig. 1). When the data were stratified according to soil texture, the relationship between the two tests in soil with high clay content $\left(\mathrm{r}^{2}=0.39 \mathrm{~ns}\right)$ was not as good as in the sandy soils $\left(\mathrm{r}^{2}=0.91 * * *\right)$. The lack of a strong relationship between the two tests in clay soils likely reflects the difference in the ability of the two tests to measure the exchangeable $\mathrm{K}$ fraction. Owing to the lower amounts of $\mathrm{K}$ removed and the mode of action of the membrane, it seems that only a portion of the 
exchangeable $\mathrm{K}$ is removed as compared to the bicarbonate extraction where most of it is removed. This would explain the large deviation in clay soils, where adsorbed $\mathrm{K}$ is large in relation to solution $\mathrm{K}$.

For nitrate and sulfate, the ACEM and $\mathrm{CaCl}_{2}$ extractions were very closely correlated ( $\mathrm{r}^{2}=0.96^{* * *}$ and $0.94^{* * *}$, respectively) (Fig. 1). A close relationship between the two tests is expected since there is no solid phase pool of ion to be included in the measurement. Rather, all the nitrate and sulfate in these soils exists in the soil solution and both tests should be effective at removing all or a consistent portion of this fraction. As expected, the relationship was not affected by stratification of the soils into groups according to $\mathrm{pH}$, texture, or soil zones.

\section{Ability of ACEM to Predict Nutrient Availability to Canola}

The relationships between nutrient uptake by canola and the predicted availability as given by the ACEM and conventional tests are provided in Table 4 and 5 . All the relationships were highly significant. The ACEM extractable $\mathrm{P}$ was more closely correlated with plant $\mathrm{P}$ uptake $\left(\mathrm{r}^{2}=0.84^{* * *}\right)$ than the Olsen $\mathrm{P}\left(\mathrm{r}^{2}=0.70^{* * *}\right)$. This finding agrees with the results reported by Naidu et al. (1991), in which exchange resin beads were found to be better predictor of plant available $\mathrm{P}$ than Olsen P. ACEM extractable $\mathrm{K}$ was also a better predictor of $\mathrm{K}$ availability to canola than the Olsen test $(\mathrm{p}=0.001)$.

The superiority of the resin membrane soil test over the conventional extractions in predicting plant $\mathrm{P}$ and $\mathrm{K}$ uptake may be interpreted as follows. Firstly, the ACEM method removes ions from the soil in a manner analogous to a plant root and causes little alteration to the surface properties of the soil because it removes solution $\mathrm{P}$ and $\mathrm{K}$, along with the most easily removed surface $\mathrm{P}$ and a portion of the exchangeable K (Amer, et al., 1955 and Pratt, 1951). Also, the $\mathrm{pH}$ of the soil suspension during the membrane extraction is close to that of the soil as it exists in the field.

Table 4. Regression equations for relationship between total uptake of $N, P, K$ and $S$ (y) by canola and ACEM extractable $N, P, K$ and $S$

\begin{tabular}{|c|c|c|c|c|}
\hline \multirow{2}{*}{$\begin{array}{l}\text { ACEM } \\
\text { extractable } \\
\text { nutrient }\end{array}$} & \multirow{2}{*}{$\begin{array}{l}\text { Linear } \\
\text { equation }\end{array}$} & \multirow{2}{*}{$\begin{array}{l}\text { Quadratic } \\
\text { equation }\end{array}$} & \multicolumn{2}{|c|}{$\begin{array}{l}\text { oefficient of determination } \\
\left(\mathrm{R}^{2}\right)\end{array}$} \\
\hline & & & Linear & Quadratic \\
\hline $\mathbf{P}$ & $y=0.2+0.5 x$ & $y=5.6 e-2+0.6 x-1.6 e-2 x^{2}$ & $0.84^{* * *}$ & $0.85 * * *$ \\
\hline $\mathrm{K}$ & $y=9.6+0.1 x$ & $y=1.6+0.4 x-1.8 e-3 x^{2}$ & $0.54 * * *$ & $0.63 * * *$ \\
\hline $\mathrm{N}$ & $y=2.4 e-2+1.4 e-3 x$ & $y=1.5 e-2+3.2 e-3 x-5.3 e-5 x^{2}$ & $0.60^{* * *}$ & $0.73 * * *$ \\
\hline $\mathbf{S}$ & $y=5.8 e-2+4.6 e-3 x$ & $y=-6.0 e-2+1.7 e-2 x-3.9 e-5 x^{2}$ & $0.70^{* * *}$ & $0.97 * * *$ \\
\hline
\end{tabular}


Table 5. Regression equations for relationship between total uptake of $\mathrm{N}, \mathrm{P}, \mathrm{K} \& \mathrm{~S}(\mathrm{y})$ by canola and $\mathrm{NaHCO}_{3}-\mathrm{P} \& \mathrm{~K}$ and $\mathrm{CaCl}_{2}-\mathrm{N} \& \mathrm{~S}$

\begin{tabular}{lllll} 
Nutrient & \multirow{2}{*}{$\begin{array}{l}\text { Linear } \\
\text { equation }\end{array}$} & \multicolumn{2}{c}{$\begin{array}{c}\text { Quadratic } \\
\text { equation }\end{array}$} & $\begin{array}{c}\text { Coefficient of determination } \\
\left(\mathrm{R}^{2}\right)\end{array}$ \\
\hline $\mathrm{P}^{\#}$ & $\mathrm{y}=-0.2+8.9 \mathrm{e}-2 \mathrm{x}$ & $\mathrm{y}=-.2+3.0 \mathrm{e}-2 \mathrm{x}+1.4 \mathrm{e}-3 \mathrm{x}^{2}$ & $0.70^{* * *}$ & $0.73^{* * *}$ \\
$\mathrm{~K}^{\#}$ & $\mathrm{y}=10.4+3.0 \mathrm{e}-2 \mathrm{x}$ & $\mathrm{y}=4.1+9.1 \mathrm{e}-2 \mathrm{x}-1.3 \mathrm{e}-4 \mathrm{x}^{2}$ & $0.37^{* * *}$ & $0.41^{* * *}$ \\
$\mathrm{~N}_{\# \#}^{\# \#}$ & $\mathrm{y}=2.2 \mathrm{e}-2+1.1 \mathrm{e}-3 \mathrm{x}$ & $\mathrm{y}=2.2 \mathrm{e}-2+2.5 \mathrm{e}-3 \mathrm{x}-3.1 \mathrm{e}-5 \mathrm{x}^{2}$ & $0.57^{* * *}$ & $0.67^{* * *}$ \\
$\mathrm{~S}^{\# \#}$ & $\mathrm{y}=7.2 \mathrm{e}-2+2.3 \mathrm{e}-3 \mathrm{x}$ & $\mathrm{y}=-7.6 \mathrm{e}-2+1.2 \mathrm{e}-2 \mathrm{x}-1.5 \mathrm{e}-5 \mathrm{x}^{2}$ & $0.61^{* * *}$ & $0.96^{* * *}$
\end{tabular}

\# extracted by $0.5 \mathrm{M} \mathrm{NaHCO}_{3}$

\#\# extracted by $0.001 \mathrm{M} \mathrm{CaCl}_{2}$

The ACEM extractable- $\mathrm{NO}_{3}$ was significantly correlated with canola $\mathrm{N}$ uptake $\left(\mathrm{r}^{2}=\right.$ $\left.0.60^{* * *}\right)$, as was $\mathrm{CaCl}_{2}$ extractable- $\mathrm{NO}_{3}\left(\mathrm{r}^{2}=0.57^{* * *}\right)$. Table 4 and 5 also show a good relationship between canola S uptake and ACEM extractable- $\mathrm{SO}_{4}\left(\mathrm{r}^{2}=0.70^{* * *}\right)$ and $\mathrm{CaCl}_{2}$ extractable- $\mathrm{SO}_{4}\left(\mathrm{r}^{2}=0.61^{* * *}\right)$. Both the ACEM and conventional tests suffer the shortcoming that they cannot account for $\mathrm{N}$ and $\mathrm{S}$ released from soil organic matter by mineralization during growing season.

Second-order polynomial regression resulted in significantly higher degrees of correlation than did linear regression between plant response parameters and soil test values for nitrate and sulfate (Table 4 and 5). It can be interpreted that the quadratic relation reflects the levelling off of plant nutrient uptake that ultimately occurs as soil nutrient status increase beyond a certain point. When we excluded the variable which was far beyond the average values in the regression analysis, the $\mathrm{r}^{2}$ for linear regression increased to $0.97 * * *$ between canola $\mathrm{S}$ uptake and ACEM extractable $\mathrm{SO}_{4}$ and $0.91^{* * *}$ between canola $\mathrm{S}$ uptake and $\mathrm{CaCl}_{2}-\mathrm{SO}_{4}$, respectively.

\section{CONCLUSION}

ACEM extraction provides a simple, rapid, simultaneous index of relative $P, K, N$ and $S$ availability in which the mode of extraction closely simulates the action of plant roots. The higher correlation between test predicted nutrient availability and actual plant uptake observed for ACEM compared to conventional tests on the wide range of soils evaluated indicates that the ACEM is a better index of relative nutrient availability. It is thus concluded the ACEM extraction is superior to existing chemical-based soil tests, especially for $\mathrm{P}$ and $\mathrm{K}$.

\section{ACKNOWLEGMENTS}

The authors wish to thank ESSO Chemical Canada, Saskatchewan Agriculture Development Fund, and the Saskatchewan Soil Testing Laboratory for support of this research. 


\section{REFERENCES}

Amer, F., D. R. Bouldin, C. A. Black and F. R. Duke. 1955. Characterization of soil phosphorus by anion exchange resin adsorption and 32P equilibration. Plant and Soil 6: 391-408.

Bowman, R. A., S. R. Olsen, and F. S. Watanabe. 1978. Greenhouse evaluation of residual phosphate by four phosphorus methods in neutral and calcareous soils. Soil Sci. Soc. Am. J. 42: 451-454.

Cooke, I. J. and J. Hislop. 1963. Use of anion-exchange resin for the assessment of available soil phosphate. Soil Sci. 96: 308-312

Frigenbaum, S., R. Edelstein and I. Shainbery. 1981. Release rate of potassium and structural cations from micas to ion exchangers in dilute solutions. Soil Sci. Soc. Am. J. 45: 501-506.

Heming, S. D. and D. L. Rowell 1985. Soil structure and potassium supply. I. The release of potassium from soil aggregates to Ca-resin. J. Soil Sci. 36: 45-60

Martin, H. W. and D. L. Sparks. 1983. Kinetics of non-exchangeable potassium release from two Coastal Plain soils. Soil Sci. Soc. Am. J. 47: 883-887.

Moser, U. S., W. H. Sutherland and C. A. Black. 1959. Evaluation of laboratory indices of absorption of soil phosphorus by plants. I. Plant and Soil 10:356 374.

Naidu, R., J. K. Syers, R. W. Tillman and J. H. Kirkman. 1991. Assessment of plant-available phosphate in limed, acid soils using several soil-testing procedures. Fertilizer Research 30: 47 - 53.

Nesse, P., I. Grava and P. R. Bloom. 1988. Correlation of several tests for phosphorus with resin extractable phosphorus for 30 alkaline soils. Commun. In Soil Sci. Plant Anal., 19: 675-689.

Olsen, S. R., C. V. Cole, F. S. Watanabe and L. A. Dean. 1954. Estimation of available phosphorus in soils by extraction with sodium bicarbonate. US Dept. of Agric. Circ. 939.

Pratt, P. F. 1951. Potassium removal from Iowa soils by greenhouse and laboratory procedures. Soil Sci. 72: 107-118.

Qian, P., J. Liang and R. E. Karamanos, 1991. Comparison of several extractants for available phosphorus and potassium. In: Soils and Crops Workshop, University of Saskatchewan, Saskatoon, Februry 21 and 22.

Saggar, S., M. J. Hedley and R.E. White. 1990. A simplified resin membrane technique for extracting phosphorus from soils. Fertilizer Research 24: 173-180.

Saunders, W. M. H. 1964. Extraction of soil phosphate by anion-exchange membrane. N.Z. J. Agr. Res. 7: 427-431. 
Schoenau, J. J. and W. Z. Huang. 1991a. Anion-exchange membrane, water, and sodium bicarbonate extractions as soil tests for phosphorus. Commun. In Soil Sci. Plant Anal. 22: 465-492.

Schoenau, J. J. and W. Z. Huang. 1991b. Assessing P,N,S and $K$ availability in soil using anion and cation exchange membranes. pp 131-136. In: Proceedings of the 1991 Western Phosphate and Sulfur Workgroup, Colorado State University, Fort Collins, Colorado.

Shi, R. ed. 1980. Testing soil for phosphorus. pp $61-78 \quad I n$ : Methods of Soil and Agricultural Chemistry Analysis, Agricultural Publishing Co., Beijing, People's Republic of China.

Sibbesen, E. 1977. A simple ion-exchange resin procedure for extracting plantavailable elements from soil. Plant and Soil 46: 665-669.

Sibbesen, E. 1978. An investigation of the anion-exchange resin method for soil phosphate extraction. Plant and Soil 50: 305-321.

Sibbesen, E. 1983. Phosphate soil tests and their suitability to assess the phosphate status of soil. J. Sci. Food Agric. 34: 1368-1374.

Skogley, E. O., S. J. Georgitis, J. E. Yang and B. E. Schaff. 1990. The phytoavailability soil test-PST. Commun. in Soil Sci. Plant Anal. 21: 1229-1243.

Tabatabai, M. A., 1982. Sulfur. pp. 501 - 538. In Pace, A. L. et al. (eds), Method of soil analysis Part 2. ASA Inc. and SSSA Inc., Madison.

Thomas, R. L., R. W. Sheard and J. P. Moyer. 1967. Comparison of conventional and automated procedures for nitrogen, phosphorus and potassium analysis of plant material using a single digest. Agron. J. 99; 240-243.

van Raij, B., J. A. Quaggio and N. M. da Silva. 1986. Extraction of phosphorus, potassium, calcium and magnesium from soils by using an ion-exchange resin procedure. Comm. Soil Sci. Plant Anal. 17: 547-566.

Walmsley, D. and I. S. Cornforth. 1973. Method of measuring available nutrients in West Indian soils. II. Phosphorus. Plant and Soil 39: 93 - 101

Yang, J. E. and J. S. Jacobsen. 1990. Soil inorganic phosphorus fractions and their uptake relationships in calcareous soils. Soil Sci. Soc. Am. J. 54: 1666-1669.

Yang, J. E., E. O. Skogley and B. E. Schaff. 1990a. Microwave radiation and incubation effects on resin-extractable nutrients. I. Nitrate, ammonium and sulfur. Soil Sci. Soc. Am. J. 54: 1639-1645.

Yang, J. E., E. O. Skogley and B. E. Schaff. 1990b. Microwave radiation and incubation effects on resin-extractable nutrients: II Potassium, calcium, magnesium, and phosphorus. Soil Sci. Soc. Am. J. 54: 1646-1650.

Yang, J. E., E. O. Skogley, S. J. Georgitis, B. E. Schaff and A. H. Ferguson. 1991. Phytoavailability soil test: Development and Verification of Theory. Soil Sci. Soc. Am. J. 55: 1358-1365. 